\author{
SERIES 'THE PLEURA' \\ Edited by H. Hamm and R.W. Light \\ Number 11 in this Series
}

\title{
Pleural disease and acquired immune deficiency syndrome
}

\author{
R.W. Light*, H. Hamm**
}

\begin{abstract}
Pleural disease and acquired immune deficiency syndrome. R.W. Light, H. Hamm. (C)ERS Journals Ltd 1997.

ABSTRACT: Patients with acquired immune deficiency syndrome (AIDS) do not frequently have pleural complications. However, pneumothorax is a troublesome complication of patients with AIDS. At some medical centres, more than $50 \%$ of patients with spontaneous pneumothorax have AIDS. Most patients with spontaneous pneumothorax and AIDS have Pneumocystis carinii infection and necrotic subpleural blebs. The pneumothoraces in these patients usually cannot be managed with tube thoracostomy alone. Patients who do not respond to tube thoracostomy are best managed with a Heimlich valve or with thoracostomy with stapling of blebs and pleural abrasion.

Approximately $2 \%$ of human immunodeficiency virus (HIV)-positive individuals will have a pleural effusion. Parapneumonic effusions or empyema, tuberculosis and Kaposi's sarcoma are the three leading causes. $P$. carinii infection is frequently responsible for pulmonary infections, but is only occasionally responsible for a pleural effusion. Pleural effusions may also develop from non-Hodgkin's lymphoma (NHL). There is one relatively rare NHL that is associated with the Kaposi's sarcoma associated virus that produces a lymphoma confined to the body cavity. Eur Respir J 1997; 10: 2638-2643.
\end{abstract}

*Pulmonary Disease Program, St Thomas Hospital, Nashville, TN, USA. **Abt. Pneumologie, Med. Universitäts Klinik, Freiburg, Germany.

\author{
Correspondence: H. Hamm \\ Abt. Pneumologie \\ Med. Universitäts Klinik \\ Hugstetter Str. 55 \\ 79106 Freiburg \\ Germany
}

Keywords: Acquired immune deficiency syndrome

human immunodeficiency virus infection pleural effusion

pneumothorax

Received: August 251997

Accepted after revision September 31997
The number of patients with acquired immune deficiency syndrome (AIDS) continues to increase and they account for a significant percentage of hospitalizations at least in some communities. Patients who have AIDS frequently have pulmonary complications and these complications at times involve the pleura, producing either a pneumothorax or a pleural effusion. This article reviews current information concerning pneumothorax and pleural effusion which occur in AIDS patients.

\section{Pneumothorax and AIDS}

The great majority of patients with AIDS who develop a spontaneous pneumothorax have Pneumocystis carinii infection $[1,2]$. The risk of spontaneous pneumothorax is also higher if the patient is receiving aerosolized pentamidine, smokes cigarettes or presents pneumatoceles on a chest radiograph [3]. Most patients have CD4+ counts less than 100 cells $\mu \mathrm{L}^{-1}$ [4]. The incidence of spontaneous pneumothorax was $4 \%$ in one series of 408 patients who were receiving prophylactic pentamidine therapy; about $25 \%$ of these patient had had $P$. carinii pneumonia previously [5]. In a more recent study from Bellevue Hospital in New York, the rate of spontaneous pneumothorax was $4.9 \%$ in a group of 1,360 patients with AIDS and $P$. carinii pneumonia [6]. At some medical centres where large numbers of patients with AIDS are treated, pneumothoraces in these patients account for a sizeable percentage of all the spontaneous pneumothoraces. At Parkland Memorial Hospital in Dallas, Texas, $27 \%$ of all cases of spontaneous pneumothorax between 1983 and 1991 occurred in patients with AIDS [7].

The reason that there is a high incidence of spontaneous pneumothorax in AIDS patients with $P$. carinii infection appears to be the presence of multiple subpleural lung cavities, which are associated with subpleural necrosis [8-11]. Most AIDS patients with $P$. carinii infection and spontaneous pneumothorax will have evidence of fibrocystic parenchymal disease [8]. When the lung is viewed at surgery, there is usually diffuse involvement of the lung parenchyma with greater involvement of the upper lobe. There are usually emphysematous blebs on the surface of the lung and multiple cysts in the apex of the lung [12]. It is common to

Previous articles in this series: No. 1: G. Miserocchi. Physiology and pathophysiology of pleural fluid turnover. Eur Respir J 1997; 10: 219-225. No. 2: R.W. Light. Diagnostic principles in pleural disease. Eur Respir J 1997; 10: 476-481. No. 3: G.T. Kinasewitz. Transudative effusions. Eur Respir J 1997; 10: 714-718. No. 4: J. Ferrer. Pleural tuberculosis. Eur Respir J 1997; 10: 942-947. No. 5: H. Hamm, R.W. Light. Parapneumonic effusion and empyema. Eur Respir J 1997; 10: 1150-1156. No. 6: G. Hillerdal. Chylothorax and pseudochylothorax. Eur Respir J 1997; 10: 1157-1162. No. 7: F.M.N.H. Schramel, P.E. Postmus, R.G.J.R.A. Vanderschueren. Current aspects of spontaneous pneumothorax. Eur Respir J 1997; 10: 1372-1379. No. 8: F. Rodriguez-Panadero, V.B. Antony. Pleurodesis: state of the art. Eur Respir J 1997; 10: 1648-1654. No. 9: S.A. Sahn. Pleural diseases related to metastatic malignancies. Eur Respir J 1997; 10: 1907-1913. No. 10: C. Kroegel, V.B. Antony. Immunology of pleural inflammation: potential implications for pathogenesis, diagnosis and therapy. Eur Respir J 1997; 10: 2411-2418. 
find areas of necrosis in consolidated areas of the lung and these areas are exceedingly friable and prone to laceration with the slightest manipulation. When lung specimens are viewed microscopically, there is usually extensive necrosis with complete loss of the inherent architecture. The reason that patients who are on aerosolized pentamidine are more likely to develop pneumothorax is not definitely known. However, it is hypothesized that aerosolized pentamidine usually does not reach the periphery of the upper lobe. Therefore, a low-grade infection persists and destroys the lung, leading to the development of the cysts and bronchopleural fistulas [13].

It is ominous when a patient with AIDS and P. carinii infection develops a spontaneous pneumothorax. In one study, the mean survival time of 22 patients with spontaneous pneumothorax was 147 days after the diagnosis of the pneumothorax [12]. In a second series, the in-hospital mortality was $29 \%$ for 35 patients with spontaneous pneumothorax. In a more recent study the in-hospital mortality of 32 patients with $P$. carinii infection and a spontaneous pneumothorax was 50\% [14].

Recurrent ipsilateral or contralateral pneumothoraces are very common in patients with AIDS and spontaneous pneumothorax. In one series of 20 patients, ipsilateral recurrences occurred in $13(65 \%)$ and contralateral pneumothoraces also occurred in $13(65 \%)$ [1].

The treatment of the spontaneous pneumothorax in the patient with AIDS is difficult. The difficulty in managing these patients is due to the fact that the visceral pleura is necrotic so that the bronchopleural fistula tends to persist [13]. Conservative therapy consisting of tube thoracostomy with or without a sclerosing agent usually fails. In one reported series 20 patients were treated with a chest tube alone and the treatment was successful in only four despite the chest tube being in place a median of 20 days [1]. In a second series only nine of 35 patients $(26 \%)$ were successfully managed with a chest tube and tetracycline/doxycycline pleurodesis [15].

Given the poor prognosis of the patient with AIDS and a spontaneous pneumothorax and the poor results with tube thoracostomy with or without sclerosing agents, alternative treatments should be considered. The initial treatment of most patients should be a chest tube. If the air-leak persists after 3 days, then there are basically two choices - a Heimlich valve or operative intervention [13].

The least invasive therapy is to attach a Heimlich valve to the chest tube and send the patient home, not worrying about the closure of the bronchopleural fistula [4]. TRACHiotis et al. [4] recently reported their experience managing AIDS patients with pneumothorax and reported that they discharged eight of 25 patients with a Heimlich valve. Of the remaining 17 patients, nine died in hospital and nine responded to tube thoracostomy with or without chemical pleurodesis [4]. The advantage of the Heimlich valve is that the patient can be managed as an outpatient, thereby shortening hospitalization [4].

If the patient cannot be managed with a Heimlich valve or if definitive treatment of the pneumothorax is desired, the treatment of choice is probably video thoracoscopy. In one series 11 of 12 patients were successfully managed with video thoracoscopy with the insufflation of 5-10 g of asbestos-free talc without treating the air leaks directly [15]; these authors hesitated to resect the area of the leak because they felt that the necrotic tissue made the resection technically difficult. However, CRAWFORD et al. [16] reported the successful management of 13 of 14 patients using thoracotomy with direct closure of the bronchopleural fistula and parietal pleurectomy. Due to the high incidence of contralateral pneumothorax, one group has recommended that patients undergo a median sternotomy incision with bilateral pleurodesis [17]. Video thoracoscopy is preferred over thoracotomy in general because it is associated with less morbidity.

\section{Pleural effusions and AIDS}

The reported prevalence of pleural effusion among patients hospitalized with AIDS has varied markedly. The prevalence of pleural effusion was only $1.7 \%$ in a very large series of 4,511 HIV positive patients who were admitted to the Metropolitan Hospital Center in New York [18]. In a second series the prevalence of pleural effusion was $18.3 \%$ in $350 \mathrm{HIV}$-positive patients in Charleston, South Carolina [19]. There is no explanation for the markedly different prevalences. In our experience, the prevalence has been closer to $2 \%$ than to $20 \%$.

The distribution of the diseases responsible for pleural effusion in patients with AIDS varies widely from series to series. In one series of 61 patients from Paris, $32(52 \%)$ of the patients had Kaposi's sarcoma (KS), 11 $(18 \%)$ had anaerobic bacterial pneumonia, nine (15\%) had tuberculous pleuritis, six $(10 \%)$ had opportunistic infections, and three $(5 \%)$ had effusions due to other malignancies [20]. In contrast in a series of 30 patients from New York, $12(40 \%)$ had parapneumonic effusion or empyema, six $(20 \%)$ had tuberculosis, three (10\%) had end-stage renal disease with volume overload, seven $(23 \%)$ had miscellaneous disease or an unknown aetiology and only two (7\%) had Kaposi's sarcoma [18]. The explanation for the differences in the above two studies is in part due to the fact that in the series from Paris most patients were homosexual (KS occurs predominantly in homosexuals) while the series from New York was predominantly intravenous drug users. As might be expected, in Rwanda, tuberculosis was responsible for 82 of 91 (90\%) of the effusions in HIVpositive patients [21]. Lastly in a series of 59 patients from South Carolina, the most common cause of pleural effusion was bacterial pneumonia (18 patients (31\%)), but hypoalbuminemia was thought to be responsible for the effusion in $11(19 \%)$ and $P$. carinii pneumonia was thought to be responsible for nine (15\%) [19]. However, a recent abstract has called into question whether hypoproteinemia itself is a cause of a transudative pleural effusion [22].

\section{Parapneumonic effusion and empyema in patients with AIDS}

The incidence of community acquired pneumonia in patients with AIDS has increased. Once a patient with 
AIDS develops pneumonia, the pneumonia is more likely to be severe. Parapneumonic effusions are more common in AIDS patients. In one study from Spain [23], the incidence of parapneumonic effusion was $21 \%$ (21 out of 99) in HIV-positive patients compared with $13 \%$ (116 out of 884 ) in HIV-negative patients. The incidence of bacteremia was $58 \%$ (11 out of 19) in patients with AIDS and parapneumonic effusion compared with $18 \%$ (17 out of 96) in patients without AIDS. The parapneumonic effusions were also more likely to be complicated in the HIV-positive individuals [23, 24]. The median pleural fluid glucose levels were lower in the HIV-positive patients [23]. The percentage of patients who required chest tubes were significantly higher in the HIV-positive group (15 out of $21,71 \%$ ) than in the HIV-negative group (51 out of $116,44 \%$ ). In addition, positive blood or pleural fluid cultures for Staphyloccoccus aureus were more common in the HIV-positive group (13 out of 17, 76\%) than in the HIV-negative group (17 out of $57,30 \%$ ) [23].

The management of patients with AIDS and parapneumonic effusion is similar to the management of the immunocompetent patient with a parapneumonic effusion. Due to the high incidence of infection with $S$. aureus, the patients should be given antibiotics that will cover this organism. Due to their immuno-incompetency, one should probably be more aggressive in placing chest tubes in these patients than in immunocompetent individuals.

\section{Tuberculous pleural effusions in patients with AIDS}

As mentioned above, in some series the most common aetiology for pleural effusions in patients with AIDS is tuberculosis [21]. Interestingly, among patients with AIDS, the percentage of tuberculosis cases that have a pleural effusion is higher in patients with CD4+ counts above 200 cells $\mu \mathrm{L}^{-1}$ than in those with CD4+ counts below 200 cells $\mu \mathrm{L}^{-1}$ [25]. This observation supports the hypothesis that tuberculosis pleuritis is predominantly due to delayed hypersensitivity rather than a direct infection of the pleural space. Patients who are coinfected with the AIDS virus have some different clinical characteristics than do patients without AIDS. The pleural fluid acid-fast bacillus (AFB) stain is positive in $\sim 15 \%$ of patients with AIDS [26] but in only $\sim 1 \%$ of patients without AIDS [13]. The pleural fluid and the sputum culture are each positive in $40-50 \%$ of patients with AIDS but in only $10-15 \%$ of patients without AIDS [27]. In patients with tuberculous pleuritis, the purified protein derivative (PPD) skin test is less likely to be positive if the patient has AIDS [26, 27].

Patients with AIDS also have significantly different findings in their pleural fluid. Measurement of the pleural fluid adenosine deaminase (ADA) levels appear to be less sensitive in identifying patients with tuberculosis in AIDS patients than in non-AIDS patients [28]. Also, levels of tumour necrosis factor alpha are significantly lower in patients with AIDS than in patients without AIDS [29]. However, the levels of interferon-gamma in the pleural fluid are raised by the same amount in patients with AIDS and pleural tuberculosis as they are in other patients with pleural tuberculosis [30].
The diagnosis of tuberculous pleuritis in HIV-infected patients is made in the same way as it is in patients who are not HIV-infected. The diagnosis is established by demonstrating AFB in the pleural fluid, sputum or pleural biopsy material or by culturing Mycobacterium tuberculosis from the sputum, pleural fluid or pleural biopsy specimen. The diagnosis can also be made by demonstrating granulomas in the pleural biopsy specimen. As mentioned above, pleural fluid ADA levels are less useful in making the diagnosis of tuberculous pleuritis in HIV-infected individuals.

The treatment of tuberculous pleuritis in HIV-infected patients is essentially the same as that for any patient with tuberculous pleuritis. The initial phase of a 6 month regimen should consist of a 2 month period of isoniazid (INH), rifampin, and pyrazinamide. Ethambutol should be included in the initial regimen until the results of drug susceptibility studies are available, unless there is little possibility of drug resistance. The second phase of the treatment should be isoniazid and rifampin given for 4 months. However, if there is evidence of a slow or sub-optimal response, therapy should be prolonged and judged on a case by case basis [31].

\section{Pleural effusions due to Kaposi's sarcoma (KS)}

$\mathrm{KS}$ is one of the most common causes of pleura effusion in patients with AIDS. Recently it has been demonstrated that deoxyribonucleic acid (DNA) sequences of the human herpes virus 8 (HHV8) can be regularly isolated from KS material and it has been hypothesized that this virus has a pathogenetic role in KS [32]. This virus is also called $\mathrm{KS}$-associated virus (KSHV). The KSHV has also been propagated from KS lesions [33].

KS occurs almost exclusively in homosexual patients with AIDS and the prevalence of KS is $20-25 \%$ in these patients $[34,35]$. The most common presentation of KS is as cutaneous violaceus plaques. Pleuropulmonary KS occurs in $\sim 20 \%$ of patients with cutaneous KS [35]. The chest radiograph of patients with pulmonary KS generally shows bilateral infiltrates [35]. Approximately $50 \%$ of patients with pulmonary KS have pleural effusions and most of them will have bilateral parenchymal infiltrates [35]. The pleural effusions may be unilateral or bilateral. The computed tomography (CT) scan of patients with pulmonary $\mathrm{KS}$ usually reveals numerous nodules, tumoural masses and bronchovascular pathways thickening [36]. In one series of 53 patients, 29 $(55 \%)$ had pleural effusions which were bilateral in $76 \%$ [36]. At autopsy, patients with pulmonary KS have multiple cherry red to purple lesions on the visceral but not on the parietal pleural surface [35].

The pathogenesis of the effusion with KS is unknown. The pathogenesis of most effusions due to malignancy has been attributed to blockade of the lymphatic drainage system which is located in the parietal pleura. We have questioned this assertion in a recent editorial [37], and feel it is particularly unlikely in patients with KS pleural effusions, since their parietal pleura is not involved. In patients with KS the pleural effusion is a chylothorax in $\sim 20 \%$ which suggests involvement of the thoracic duct by the tumour in these cases. In the remainder of the patients with KS and pleural effusion, 
we hypothesize that the effusion is due to the elaboration of vascular endothelial growth factor (VEGF). VEGF is elaborated by many tumours and promotes microvascular hyperpermeability so that extravascular fluid is formed [38]. VEGF is present in large quantities in AIDS-KS cell-derived conditioned media [39]. It is, therefore, quite possible that VEGF could be responsible for the pleural effusion. In addition, many of the effusions are bloody and this could also be explained by VEGF since VEGF is also angiogenic [38].

The definitive diagnosis of pleural KS is not easy. The pleural fluid is an exudate that is usually serosanguineous or haemorrhagic. The diagnosis cannot be established with cytology because the diagnosis requires a characteristic architectural appearance and not a particular neoplastic cell type [34]. The diagnosis cannot be made with needle biopsy of the pleura because the parietal pleural is not involved. The diagnosis can be established by thoracoscopy with the characteristic appearance of the KS lesions on the visceral pleura [35]. One report several years ago suggested that the diagnosis could be made by immunocytochemical staining of the cells in the pleural fluid with CD34 antibody, a newly recognized marker for vascular neoplasia [40]. However, since there have been no confirmatory reports since the original one, its validity must be questioned. In most cases a presumptive diagnosis is based on the clinical picture and the characteristic bronchoscopic picture [41].

The treatment of the pleural effusion secondary to KS is difficult. Tube thoracostomy with the instillation of tetracycline is usually not successful. Insufflated talc is probably the treatment of choice if the diagnosis is made with thoracoscopy. Otherwise, pleurodesis via talc in a slurry or a pleuroperitoneal shunt are probably the best alternatives.

\section{Pleural effusion due to lymphomas}

Malignant lymphomas represent the second most common neoplasm associated with HIV infection [42]. Most AIDS-related lymphomas are B-cell non-Hodgkin's lymphoma (NHL) and most can be classified as Burkitt-like $(40 \%)$, large cell $(30 \%)$ and large cell immunoblastic (30\%) lymphoma [42]. The incidence of NHL in HIVinfected individuals is estimated to be 60-100 times higher than expected [42]. A less common type of NHL is the KSHV related lymphoma. This uncommon lymphoma grows mainly in the body cavities and presents as a lymphocyte predominant effusion without an identifiable contiguous tumour mass [43]. The consistent presence of KSHV and certain other features suggest that this is a distinct entity. In one series [44], KSHV was sought in lymphomas from 42 patients with AIDS. All eight of the body-cavity-based lymphomas were associated with KSHV while none of the other 34 lymphomas were [44].

In a recent article NADOR et al. [43] studied 19 malignant lymphocyte-predominant pleural effusions occurring in the absence of a contiguous tumour mass for their clinical, morphological, immunophenotypic, viral, and molecular characteristics. They found that KSHV was present in 15 of the 19 lymphomas. All four KSHV negative lymphomatous effusions exhibited Burkitt or Burkitt-like morphology and c-myc gene rearrangements and therefore appeared to be Burkitt-type lymphomas. In contrast the KSHV-positive lymphomas exhibited a distinctive morphology bridging large-cell immunoblastic lymphoma and anaplastic large-cell lymphoma and all lacked the c-myc gene rearrangements. Of the KSHVpositive lymphomas, all occurred in men, 13 out of 15 in association with HIV infection, in all of which homosexuality was a risk factor. Of these 15 cases, 14 presented as a lymphocyte-predominant effusion and 13 remained localized to the body cavity of origin.

At times pleural effusions are seen in conjunction with NHL which is unrelated to KSHV. Between 6 and $30 \%$ of patients with NHL and AIDS will have intrathoracic involvement [45]. EISNER et al [46] reviewed the clinical characteristics of 38 patients with HIV infection, NHL, and pulmonary involvement. Thoracic CT revealed pleural effusions in 26. The pleural effusion was bilateral in 23 and unilateral in 15. Other radiographic abnormalities in the 38 patients included lobar consolidation in 15 , pulmonary nodules in 15 , reticular infiltrates in nine and mass in nine. Certainly some of these 38 patients had KSHV associated lymphoma, but the majority did not.

The pleural fluid in these patients is an exudate and is characterized by a very high lactic acid dehydrogenase (LDH) level. In one series, the mean LDH was $2,535 \mathrm{IU} \cdot \mathrm{L}^{-1}$ and the ratio of pleural to serum LDH was 3.12 [46]. The diagnosis can usually be established with pleural fluid cytology [46].

The prognosis of patients with AIDS-associated lymphoma is poor, with a median survival of 4-6 months [44]. It is still unknown whether it is better to treat these patients aggressively or conservatively. The aggressiveness of the tumour suggests that intensive therapy would be advantageous, but there has been a high frequency of death from infections in those treated intensively [44].

\section{Pleura effusions due to P. carinii pneumonia}

Although $P$. carinii is a frequent cause of pulmonary infiltrates in the patient with AIDS, it is an unusual cause of pleural effusion. Only seven cases of pleural effusion due to $P$. carinii had been reported up until 1993 [47, 48]. All seven of these patients were receiving aerosolized pentamidine, and five of the seven had documented $P$. carinii pneumonia [13]. It appears the Pneumocystis pleural disease is an extension of smouldering subpleural $P$. carinii pneumonia and the prognosis is similar to that for patients with pneumonia alone [13]. A bronchopleural fistula was present in four of the seven patients with $P$. carinii pleural effusion [47].

The pleural fluid of patients with Pneumocystis pleural effusion has an LDH which exceeds the upper limit of normal for serum and the pleural fluid to serum LDH ratio has exceeded 1.0. However, the pleural fluid protein level has been below $3.0 \mathrm{gm} \cdot \mathrm{dL}^{-1}$ in all patients. The differential cell count can reveal either neutrophils or mononuclear cells and the pleural fluid glucose and $\mathrm{pH}$ are not reduced [47]. The presence of the pleural effusion does not alter the drug treatment of pulmonary 
Pneumocystis infection. However, if a bronchopleural fistula is present, a chest tube should be inserted.

\section{Miscellaneous cause of pleural effusions}

On occasion other opportunistic diseases such as cryptococcosis [49], nocardiosis [50], histoplasmosis [51], aspergillosis [52], or atypical mycobacteria [53] are responsible for an exudative pleural effusion in the patient with AIDS. In addition, systemic problems such as left ventricular failure or renal failure may cause transudative pleural effusions.

\section{References}

1. Sepkowitz KA, Telzak EE, Gold JW, et al. Pneumothorax in AIDS. Ann Intern Med 1991; 114: 455-459.

2. Coker RJ, Moss F, Peters B, et al. Pneumothorax in patients with AIDS. Respir Med 1993; 87: 43-47.

3. Metersky ML, Colt HG, Olson LK, Shanks TG. AIDSrelated spontaneous pneumothorax: risk factors and treatment. Chest 1995; 108: 946-951.

4. Trachiotis GD, Vricella LA, Alyono D, Aaron BL, Hix WR. Management of AIDS-related pneumothorax. Ann Thorac Surg 1996; 62: 1608-1613.

5. Leoung GS, Feigal DW Jr, Montgomery AB, Corkery $\mathrm{K}$, Wardlaw L, Adams M, et al. Aerosolized pentamidine for prophylaxis against Pneumocystis carinii pneumonia. N Engl J Med 1990; 323: 769-775.

6. Pastores SM, Garay SM, Naidich DP, Rom WN. Review: pneumothorax in patients with AIDS-related Pneumocystis carinii pneumonia. Am J Med Sci 1996; 312: 229-234.

7. Wait MA, Estrera A. Changing clinical spectrum of spontaneous pneumothorax. Am J Surg 1992; 164: 528-531.

8. Newsome GS, Ward DJ, Pierce PF. Spontaneous pneumothorax in patients with acquired immunodeficiency syndrome treated with prophylactic aerosolized pentamidine. Arch Intern Med 1990; 150: 2167-2168.

9. Shanley DJ, Luyckx BA, Haggerty MF, Murphy TF. Spontaneous pneumothorax in AIDS patients with recurrent Pneumocystis carinii pneumonia despite aerosolized pentamidine prophylaxis. Chest 1991; 99: 502-504.

10. Scannell KA. Pneumothoraces and Pneumocystis carinii pneumonia in two AIDS patients receiving aerosolized pentamidine. Chest 1990; 97: 479-480.

11. Beers MF, Sohn M, Swartz M. Recurrent pneumothorax in AIDS patients with Pneumocystis pneumonia: a clinicopathologic report of three cases and review of the literature. Chest 1990; 98: 266-270.

12. Gerein AN, Brumwell ML, Lawson LM, Chan NH, Montaner JS. Surgical management of pneumothorax in patients with acquired immunodeficiency syndrome. Arch Surg 1991; 126: 1272-1276.

13. Light RW. Pleural Diseases. Third Edition. Baltimore, Williams and Wilkins, 1995.

14. Ingram RJ, Call S, Andrade A, White C, Wheeler D. Management and outcome of pneumothoraces in patients infected with human immunodeficiency virus. Clin Infect Dis 1996; 23: 624-627.

15. Wait MA, Dal Nogare AR. Treatment of AIDS-related spontaneous pneumothorax. Chest 1994; 106: 693-696.

16. Crawford BK, Galloway AC, Boyd AD, Spencer FC. Treatment of AIDS-related bronchopleural fistula by pleurectomy. Ann Thorac Surg 1992; 54: 212-213.
17. Byrnes TA, Brevig JK, Yeoh CB. Pneumothorax in patients with acquired immunodeficiency syndrome. $J$ Thorac Cardiovas Surg 1990; 98: 546-550.

18. Lababidi HMS, Gupta K, Newman T, Fuleihan FJD. A retrospective analysis of pleural effusion in human immunodeficiency virus infected patients. Chest 1994; 106: 86S.

19. Joseph J, Strange C, Sahn SA. Pleural effusions in hospitalized patients with AIDS. Ann Intern Med 1993; 118: 856-869.

20. Cadranel JL, Chouaid C, Denis M, Lebeau B, Akoun GM, Mayaud CM. Causes of pleural effusion in 75 HIV-infected patients (letter). Chest 1993; 104: 655.

21. Batungwanayo J, Taelman H, Allen S, Bogaerts J, Kagame A, Van de Perre P. Pleural effusion, tuberculosis and HIV-1 infection in Kigali, Rwanda. AIDS 1993; 7: 73-79.

22. Eid AA, Kinasewitz GT. Hypoalbuminemia as a cause of pleural effusions. Am J Respir Crit Care Med 1997; 155: 149A.

23. Suay V, Cordero PJ, Martinez E, et al. Parapneumonic effusions secondary to community-acquired bacterial pneumonia in human immunodeficiency virus-infected patients. Eur Respir J 1995; 8: 1934-1939.

24. Rodriguez Barradas MC, Musher DM, Hamill RJ, Dowell M, Bagwell JT, Sanders CV. Unusual manifestations of pneumococcal infection in human immunodeficiency virus-infected individuals: the past revisited. Clin Infect Dis 1992; 14: 192-199.

25. Jones BE, Young SMM, Antoniskis D, Davidson PT, Kramer F, Barnes PF. Relationship of the manifestations of tuberculosis to CD4 cell counts in patients with human immunodeficiency virus infection. Am Rev Respir Dis 1993; 148: 1292-1297.

26. Relkin F, Aranda CP, Garay SM, Smith R, Berkowitz KA, Rom WN. Pleural tuberculosis and HIV infection. Chest 1994; 105: 1338-1341.

27. Cordero PJ, Gil Suay V, Greses JV, et al. The clinical characteristics of pleural tuberculosis in patients with and without human immunodeficiency virus infection. (Translated from Spanish). Arch Bronconeumol 1995; 31: 512-518.

28. Hsu WH, Chiang CD, Huang PL. Diagnostic value of pleural adenosine deaminase in tuberculous effusions of immunocompromised hosts. J Formosan Med Assoc 1993; 92: 668-670.

29. Villena MV, Echave-Sustaeta JM, Encuentra AL. Factor de necrosis tumoral alfa en liquido pleural de pacientes con tuberculosis pleural: relation con la infeccion por virus de la inmunodeficiencia humana. Arch Bronconeum 1996; 32: 434.

30. Villena V, Lopez-Encuetra A, Echave-Sustaeta J, MartinEscribano P, Ortuno-de-Solo B, Estenoz-Alfaro J. Diagnosis of pleural tuberculosis using pleural interferon gamma. Am J Respir Crit Care Med 1994; 149: A1103.

31. Bass JB Jr, Farer LS, Hopewell PC, et al. Treatment of tuberculosis and tuberculosis infection in adults and children. Am J Respir Crit Care Med 1994; 149: 13591374.

32. Cesarman E, Chang Y, Moore PS, Said JW, Knowles DM. Kaposi's sarcoma-associated herpesvirus-like DNA sequences in AIDS-related body-cavity-based lymphomas. N Engl J Med 1995; 332: 1186-1191.

33. Foreman KE, Friborg J Jr, Kong WP, et al. Propagation of a human herpesvirus from AIDS-associated Kaposi's sarcoma. N Engl J Med 1997; 336: 163-171.

34. Ognibene FP, Shelhamer JH. Kaposi's sarcoma: in pulmonary effects of AIDS. Clin Chest Med 1988; 9: 459-463. 
35. O'Brien RF, Cohn DL. Serosanguineous pleural effusions in AIDS-associated Kaposi's sarcoma. Chest 1989; 96: 460-466.

36. Khalil AM, Carette MF, Cadranel JL, Mayaud CM, Bigot JM. Intrathoracic Kaposi's sarcoma: CT findings. Chest 1995; 108: 1622-1626.

37. Light RW, Hamm H. Malignant pleural effusion: would the real cause please stand up? Eur Respir J 1997; 10: 1701-1702.

38. Brown LF, Detmar M, Claffey K, et al. Vascular permeability factor/vascular endothelial growth factor: a multifunctional angiogenic cytokine. EXS 1997; 79 . 233-269.

39. Nakamura S, Murakami-Mori K, Rao N, Weich HA, Rajeev B. Vascular endothelial growth factor is a potent angiogenic factor in AIDS-associated Kaposi's sarcomaderived spindle cells. J Immunol 1997; 158: 4992-5001.

40. Yang GC, Brooks JJ, Roberts S, Gupta PK. The detection of acquired immunodeficiency syndrome-associated Kaposi sarcoma cells in pleural effusion by CD34 immunostain. Cancer 1993; 72: 2260-2265.

41. Huang L, Schnapp LM, Gruden JF, Hopewell PC, Stansell JD. Presentation of AIDS-related pulmonary Kaposi's sarcoma diagnosed by bronchoscopy. Am J Respir Crit Care Med 1996; 153: 1385-1390.

42. Cesarman E, Knowles DM. Kaposi's sarcoma-associated herpesvirus: a lymphotropic human herpesvirus associated with Kaposi's sarcoma, primary effusion lymphoma, and multicentric Castleman's disease. Semin Diagn Pathol 1997; 14: 54-66.

43. Nador RG, Cesarman E, Chadburn A, et al. Primary effusion lymphoma: a distinct clinicopathologic entity associated with the Kaposi's sarcoma-associated herpes virus. Blood 1996; 88: 645-656.
44. White DA. Pulmonary complications of HIV-associated malignancies. Clin Chest Med 1996; 17: 755-761.

45. Cesarman E, Nador RG, Aozasa K, Delsol G, Said JW, Knowles DM. Kaposi's sarcoma-associated herpesvirus in non-AIDS related lymphomas occurring in body cavities. Am J Pathol 1996; 149: 53-57.

46. Eisner MD, Kaplan LD, Herndier B, Stulbarg MS. The pulmonary manifestations of AIDS-related non-Hodgkin's lymphoma. Chest 1996; 110: 729-736.

47. Horowitz ML, Schiff M, Samuels J, Russo R, Schnader J. Pneumocystis carinii pleural effusion: pathogenesis and pleural fluid analysis. Am Rev Respir Dis 1993; 148: 232-234.

48. Jayes RL, Kamerow HN, Hasselquist SM, Delaney MD, Parenti DM. Disseminated pneumocystosis presenting as a pleural effusion. Chest 1993; 103: 306-308.

49. Newman TG, Soni A, Acaron S, Huang CT. Pleural cryptococcosis in the acquired immune deficiency syndrome. Chest 1987; 91: 459-460.

50. Uttamchandani RB, Daikos GL, Reyes RR, et al. Nocardiosis in 30 patients with advanced human immunodeficiency virus infection: clinical features and outcome. Clin Infect Dis 1994; 18: 348-353.

51. Ankoblah WA, Vaidya K, Powell S, et al. Disseminated histoplasmosis in AIDS: clinicopathologic features in seven patients from a non-endemic area. NY State J Med 1990; 90: 234-238.

52. Staples CA, Kang EY, Wright JL, Phillips P, Muller NL. Invasive pulmonary aspergillosis in AIDS: radiographic, CT, and pathologic findings. Radiology 1995; 196: 409-414.

53. Aronchick JM, Miller WT. Disseminated nontuberculous mycobacterial infections in immunosuppressed patients. Sem Roentgenol 1993; 28: 150-157. 